\title{
Spatial Structure Analysis Of Tourist Attraction In Lanzhou Based On GIS
}

\author{
Wang Rong \\ College of Geography and Environment science, \\ Northwest Normal University \\ Lanzhou, China \\ e-mail: 1198783044@QQ.com \\ Shi Hui Chun \\ College of Geography and Environment science, \\ Northwest Normal University \\ Lanzhou, China
}

\begin{abstract}
Selects 58 tourist attraction in Lanzhou,based on GIS, analyses its Spatial structure by means of Nearest Neighbor Index,Geographic Concentration Index and Gini Coefficient index;calculates the spatial accessibility of tourist attraction using cost weighted distance method.Analysis showed:the whole,the Nearest Neighbor Index of Lanzhou tourist attractions is 0.77 ,exhibit an aggregated and uneven distribution.the internal differences of Spatial structure is evident,the Nearest Neighbor Index of Chengguan is 0.56 ,the lowest,the highest is Gaolan county,about 1.23.To provide a reference through this research for the sustainable development of tourism in Lanzhou.
\end{abstract}

Keywords-GIS;spatial structure;spatial accessibility;tourist attraction;Lanzhou

\section{INTRODUCTION}

Tourism resources is the basis of regional tourism development,is a key factor in tourist destinations to attract tourists arriving[1].The structure of tourism resource is the combination relationship of the distribution, the quality and quantity of tourism resources in the region, and tourism regional spatial competition is relying on the structure of tourism resource[2].On already existing research results, the research on the spatial structure of tourism earlier, began in the $1960 \mathrm{~s}$, has presented different "tourist spatial structure model."[3]

In recent years, many scholars has been studied the spatial structure of tourism resources. Such as: Pan Jing $\mathrm{Hu}$ using the methods of spatial econometric geographic quantitative analysis the distribution pattern China A-class tourist attractions;[4]using GIS raster cost weighted distance algorithm analyzes the attractions spatial accessibility about the China 4A level and above;[5]Using raster cost weighted distance analyzes the accessibility of China National Forest Park in 1991 and 2010.[6]

At present,there have few studies about Lanzhou attractions,Some of it is based on qualitative researchbased study, less quantitative research methods, especially the use of Arcgis software and reachability analysis. This paper is mainly based Arcgis9.2 software, using quantitative research methods of the most adjacent index, concentration index, Gini coefficient, in order to optimize

\author{
Wang Dan \\ CollegeInstitute of Education,Northwest Normal \\ University \\ Lanzhou, China
}

the spatial pattern of tourist attractions, scientific and rational development of tourism resources and better development of tourism,we studied the spatial structure of Lanzhou 58 tourist attractions.

\section{THE GENERAL SITUATION IN THE STUDY AREA}

\section{A. The general situation in the Lanzhou city}

Lanzhou City, located at latitude $36^{\circ} 03^{\prime}$, longitude $103^{\circ} 49^{\prime}$ terrain Complex and varied,belong to the transition zone of Monsoon region the non-monsoon region, arid and semiarid region.Complex and varied terrain,Long history and culture make Lanzhou have so rich diverse types of tourism resources. in 2005 was named outstanding Chinese tourist city of China Tourism Bureau.

\section{B. Lanzhou tourism resource classification}

Tourism resources according to the hierarchy of descending order is divided into 3 view series, 10 classes and 98 King type by new tourism resource classification system[7].According to this system, detailed statistics introduced the tourism resources of Lanzhou City.The results show that tourism resources of Lanzhou 3 view series is complete, $10 \mathrm{King}$ occupies 7 categories, There are 46 King type in 98.Specific allocation: the city's total 256 resources monomer, which is a natural view series has 70 , is a human view series has 152 , is the service view series has 34 .

\section{DATA SOURCES AND METHODS}

\section{A. Data Sources}

The data of Attractions used in this article from the Gansu Provincial Tourism Bureau official website(http://www.gsta.gov.cn),space administrative boundary data from the vectorization of 1: 400 million Chinese basic geographic information database,road data from the vectorization of Gansu Province atlas [8].

\section{B. Maintaining the Integrity of the Specifications}

The template is used to format your paper and style the text. All margins, column widths, line spaces, and text fonts are prescribed; please do not alter them. You may 
note peculiarities. For example, the head margin in this template measures proportionately more than is customary. This measurement and others are deliberate, using specifications that anticipate your paper as one part of the entire proceedings, and not as an independent document. Please do not revise any of the current designations.

\section{1) Research methods}

a) Nearest Neighbor Index :Nearest Neighbor index [9] is the primary method of Study tourist attractions spatial distribution types.Calculation process:first find the theorematic nearest neighbor distance $\mathrm{rE}$ (that is the degree of dotted things adjacent to each other in geographic space), then find the nearest neighbor index $\mathrm{R}$ (the ratio of actual nearest neighbor distance $\bar{r}$ and theorematic nearest neighbor distance). It is calculated as:

$$
R=\frac{\mathbf{r} E}{\bar{r}}
$$

b) Concentration Index:Geographic concentration index[10] is an important indicator to measure the degree of concentration of the research object.In this paper, we use this method measures the distribution of 58 attractions in Lanzhou.

$$
G=100 \times \sqrt{\sum_{i=1}^{n}\left(\frac{X i}{T}\right)^{2}}
$$

In the formula: $G$ is the geographic concentration index of the research object, $\mathrm{Xi}$ is the number of $\mathrm{i}$-th research area, $T$ is the total number of research object, $n$ is the number of regional studies. Value greater geographic concentration index $\mathrm{G}$, indicating that the more concentrated the distribution of the research object; on the contrary, the smaller the value,the more dispersed distribution.

c) Gini coefficient:The Gini coefficient[11] is a index of comparative difference of geographic features of the spatial distribution,it is an important method described in discrete areas of geography spatial distribution.It is calculated as:

$$
G \mathrm{ini}=-\frac{\sum_{i=1}^{n} p_{i} \operatorname{In} p_{i}}{\operatorname{In} N}
$$

In the formula:Gini is Gini coefficient; pi is the district,s percentage of the research object ; $\mathrm{N}$ is the number of partitions. Theoretically its value at between $0-1$, larger value indicates a higher degree of concentration.

d) Accessibility Index: Use GIS raster consuming distance to calculate the accessibility of Attractions."Total distance algorithm" refers to by means of shortest path based on raster data to calculate the shortest weighted distance from each grid to a destination grid. The formula is:

$$
A=\left\{\begin{array}{c}
\frac{1}{2} \sum_{i=1}^{n}\left(C_{i}+C_{i+1}\right) \\
\frac{\sqrt{2}}{2} \sum_{i=1}^{n}\left(C_{i}+C_{i+1}\right)
\end{array}\right.
$$

\section{RESUlTS AND ANALYSIS}

\section{A. Nearest Neighbor Index}

Using(1) calculated the theory Closest,estimated the actual nearest distance by using Arcgis9.2 software,get the Nearest Neighbor index and the type of the spatial structure of Lanzhou districts (TABLE.I).

TABLE I. THE NEAREST DISTANCE OF TOURIST ATTRACTION IN LANZHOU

\begin{tabular}{|c|c|c|c|c|}
\hline District & $\begin{array}{c}\text { The } \\
\text { actual } \\
\text { nearest } \\
\text { neighbor } \\
\text { distance/ } \\
\mathrm{k}\end{array}$ & $\begin{array}{c}\text { The } \\
\text { Theory } \\
\text { nearest } \\
\text { neighbor } \\
\text { distance/ } \\
\mathrm{km}\end{array}$ & $\begin{array}{c}\text { Nearest } \\
\text { Neighbo } \\
\mathrm{r} \text { Index }\end{array}$ & $\begin{array}{c}\text { Spatial } \\
\text { structure type }\end{array}$ \\
\hline Anning & 1.0202 & 1.5542 & 0.6564 & concentrated \\
\hline Xigu & 5.2733 & 4.9054 & 1.0750 & dispersed \\
\hline Chengguan & 1.2372 & 2.2361 & 0.5533 & concentrated \\
\hline Honggu & 5.8700 & 6.9222 & 0.8481 & concentrated \\
\hline Qilihe & 3.696 & 3.7556 & 0.9840 & concentrated \\
\hline Yuzhong & 11.1549 & 10.9577 & 1.0180 & dispersed \\
\hline Gaolan & 17.9925 & 14.5946 & 1.2328 & dispersed \\
\hline Yongdeng & 8.1800 & 10.428 & 0.7844 & concentrated \\
\hline Lanzhou & 5.7304 & 7.6751 & 0.7727 & concentrated \\
\hline
\end{tabular}

Analysis showed:Lanzhou tourist attractions are concentrated in the region is the Chengguan District, Anning District,Honggu District,Qilihe District, Yongdeng County, accounting for $75.86 \%$, Nearest Neighbor Index lowest is Chengguan District, followed by the Anning District;there are dispersed in the region is the Xigu District,Gaolan County, Yuzhong County, accounting for $24.14 \%$, the highest index is Gaolan County, followed by the Xigu District; Overall, the Nearest Neighbor Index of the tourist attractions distribution in Lanzhou is 0.77 , belonging to a concentrated distribution.

\section{B. Concentration Index}

Calculated Lanzhou 58 attractions geographic concentration index $\mathrm{G}=39.6927$, if the 58 attractions evenly distributed in Lanzhou,its geographic concentration index $\mathrm{G}=35.355$. Because 39.6927> 35.355, so attractions in Lanzhou was concentrated situation. 




Figure 1. The distribution of tourist attraction in Lanzhou

From the view of traffic:the attractions main concentrated in transit along the route, especially along the Yellow River and the railway line,especially along the Yellow River and the railway line;From the view of administrative, the attractions main concentrated in Chenguan,Anning,Qilihe in Lanzhou urban district,from comprehensive to look: the attractions mainly distributed along the Yellow River and railway in Lanzhou city.

\section{Balance Degree}

After calculation, the Gini coefficient of Lanzhou attractions Gini $=0.891$,described 58 attractions were concentrated; $\mathrm{C}=1-0.891=0.109$, described the spatial distribution evenness is low(TABLE.II) .

TABLE II

THE SPATIAL DISTRIBUTION OF TOURIST ATTRACTION IN LANZHOU

\begin{tabular}{|c|c|c|c|}
\hline District & $\begin{array}{c}\text { Number } \\
\text { Attractions/ge }\end{array}$ & Proportion/\% & $\begin{array}{l}\text { Cumulative } \\
\text { proportion/\% }\end{array}$ \\
\hline Anning & \multirow{5}{*}{34} & \multirow{5}{*}{58.62} & \multirow{5}{*}{58.62} \\
\hline Xigu & & & \\
\hline Chengguan & & & \\
\hline Honggu & & & \\
\hline Qilihe & & & \\
\hline Yongdeng & 14 & 24.14 & 82.76 \\
\hline Yuzhong & 7 & 12.07 & 94.83 \\
\hline Gaolan & 3 & 5.17 & 100 \\
\hline
\end{tabular}

\section{A. Attractions density}

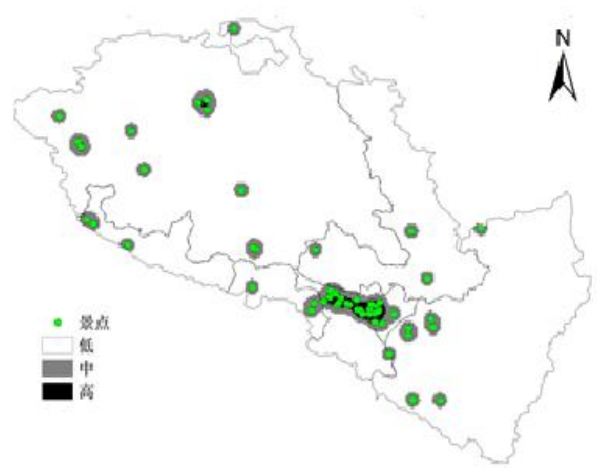

Figure 2. Density of distribution of tourist attraction in Lanzhou

Use Arcgis9.2 software produced 58 attractions density map (Fig.2).can be seen from the map showing the characteristics of attractions is punctate distribution, with two high values area of density distribution:along the Yellow River in Lanzhou downtown area,North Central of Yongdeng.In addition to various area attractions distribution is more independent, is difficult to form a cluster distribution.

\section{B. Accessibility analysis of tourist attractions}

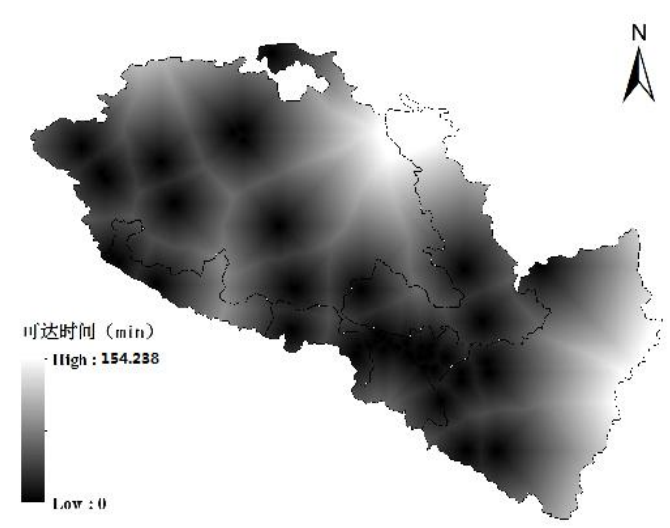

Figure 3. Accessibility of tourist attraction in Lanzhou

Overall,the accessibility of Lanzhou tourist attractions is better,The region of Accessibility within $25 \mathrm{~min}$ accounted for 44.93 percent,within $50 \mathrm{~min}$ accounted for 74.73 percent,more than $125 \mathrm{~min}$ accounted for 4.35 percent.the worst of Accessibility is the edge of the eastern and the northern of Gaolan,over $150 \mathrm{~min}$, the average up time attractions is $40.83 \mathrm{~min}$.

To $25 \mathrm{~min}$ as a staging point, the Lanzhou Attractions accessibility is divided into six time periods, namely: 0 25min, $25 \sim 50 \mathrm{~min}, 50 \sim 75 \mathrm{~min}, 75 \sim 100 \mathrm{~min}, 100 \sim$ $125 \mathrm{~min}$ and greater than $125 \mathrm{~min}$, figure by color show from deep to shallow. This six time periods to calculate the spatial distribution of the frequency and cumulative frequency (TABLE.III ).

TABLE III. DISTRIBUTION FREQUENCY AND CUMULATE FREQUENCY OF SPATIAL ACCESSIBILITY TIME OF TOURIST ATTRACTION IN LANZHOU

\begin{tabular}{|c|c|c|c|c|c|c|}
\hline time & $0 \sim 25$ & $25 \sim 50$ & $50 \sim 7$ & $75 \sim 10$ & $100 \sim 12$ & $>12$ \\
& & & 5 & 0 & 5 & 5 \\
\hline $\begin{array}{c}\text { distribute } \\
(\%)\end{array}$ & 24.9 & 29.80 & 19.4 & 13.08 & 8.43 & 4.35 \\
\hline $\begin{array}{c}\text { accumulative } \\
(\%)\end{array}$ & 24.9 & 54.73 & 74.1 & 87.22 & 95.65 & 100 \\
& 3 & & 4 & & & \\
\hline
\end{tabular}

As can be seen from the chart, attractions accessibility in $25 \sim 50 \mathrm{~min}$ is the most widely distributed, accounting for 29.80 percent of the total area; followed within $25 \mathrm{~min}$, accounting for 24.93 percent; the region of accessibility poor distribution less, the region of more than $125 \mathrm{~min}$ account for 4.35 percent of the total area. Overall,as the time increase,the distribution of frequency increases after the first showing a decreasing trend, the increase is gentle, about 5 percent, steeper decrease of about $9 \%$, showing the inverted "V" word type of distribution structure.The 
accessibility of Lanzhou attractions is better,average accessibility time is 40.84 percent,nearly 75 percent of regional accessibility within $50 \mathrm{~min}, 125 \mathrm{~min}$ region accounted for more than 4.35 percent.

\section{CONCLUSIONS}

Attractions of Lanzhou generally exhibit the characteristics of concentrated distribution,Nearest Neighbor Index was $0.77<1$; internal differences, the minimum of Nearest Neighbor Index is Chengguan District,the value of 0.55 , the largest is Gaolan County, was 1.23 , a difference of 0.68 ,the distribution of Lanzhou tourist attractions mainly concentrated in urban areas along the Yellow River and along the railway line;Lanzhou Attractions showing uneven distribution characteristics, 58.62 percent of the attractions located in Lanzhou urban district ;the distribution density of attractions Showing two high-value area: along the Yellow River in Lanzhou downtown area,North Central of Yongdeng.and the remaining attractions distribution is more independent, it is difficult to form a cluster distribution; The accessibility of Lanzhou attractions is better,average accessibility time is 40.84 percent,nearly 75 percent of regional accessibility within $50 \mathrm{~min}, 125 \mathrm{~min}$ region accounted for more than 4.35 percent.

\section{REFERENCES}

[1] Zhoucheng.Spatial structure of Tourist Resources in Shanxi Province[J].Henan science,2012,11(11):1676.

[2] Shen Zheng ping. A Study on the Structure and the Development Allocation of Tourist Resources in the Economic Belt of the New
Eurasian Continental Bridge in China.[J].Scientia geographica sinica,2002,22(2):176-183.

[3] Christaller W.Some considerations of tourism location in Europe:The peripheral region-under developed countries recreation areas[J].Regional science Association,1964,12(1):95-105.

[4] Pan Jing hu.Analysis on spatial structure of A-Grade science spots in china based on quantitative geography model[J].Economic geography,2013,33(9):154-160.

[5] Pan Jing hu.Spatial accessibility of scenic spot at 4A level and above in china[J].Scientia geographica sinica,2012,32(11):13221327.

[6] Pan Jing hu.Measurements for spatial accessibility of national forest parks in china.[J].Resources and Environment in the Yangtze Basin,2013,22(9):1181_-1187.

[7] Wei Wei,ChenJing hua.Research on spatial structure of scenic spot in zhejiang province based on geographic mathematics method.[J]. Toursim Research,2012,4(3):39-44.

[8] Pan Jinghu,MA Chuntian,LI Junfeng.Spatial structure of A-grade tourist attractions in Gansu[J].Journal of Arid Land Resources and Environment,2014,28(7):188-193.

[9] Yuan Jun,Yu Rui lin.Research on spatial structure of national AGrade tourist districts of wuhan metropolitan area.[J].Economic Geography,2010,30(2):324-328.

[10] Wei Wei,Chen Jing hua.Research on spatial structure of scenic spot in zhejiang province based on geographic mathematics method.[J]. Toursim Research,2012,4(3):39-44.

[11] Pan Jinghu,Ma Chuntian,LI Junfeng.Spatial structure of A-grade tourist attractions in Gansu[J].Journal of Arid Land Resources and Environment,2014,28(7):188-193.

[12] Jin Cheng,Lu Yu qi,Fan Li li.Research on accessibility of scenic spots in the Yangtze River Delta Based on Land Traffic Network[J].Journal of natural resources,2010,25( 2) : 258-269. 